\title{
Profit Tax Competition and Formula Apportionment
}

\section{Rüdiger Pethig and Andreas Wagener*}

\author{
VWL IV, FB 5 \\ University of Siegen \\ Hölderlinstr. 3 \\ 57068 Siegen, Germany \\ Phone/Fax: +49 - 271 - $7403164 / 2732$ \\ e-mail: pethig@vwl.wiwi.uni-siegen.de \\ wagener@vwl.wiwi.uni-siegen.de
}

\begin{abstract}
We analyse tax competition with corporate profit taxes in a common market where tax revenues are allocated according to an apportionment formula. As a general rule, tax competition is sharper the higher is the tax elasticity of the apportionment formula which, in turn, depends on the properties of production technologies. In particular: (i) If labour input is fixed, tax competition is sharpest if apportionment is based on property shares, followed by the sales and payroll shares. (ii) If capital and labour are endogenous and technologies are Cobb-Douglas, tax competition under the property- and the payroll-share rule is sharper than under the output-share formula. Whether payroll- or property-share apportionment generates sharper tax competition depends on factor elasticities.
\end{abstract}

JEL-classification: D81, D21.

Keywords: $\quad$ Tax Competition, Formula Apportionment.

\footnotetext{
${ }^{*}$ Corresponding author.
} 


\section{Introduction}

It is widely acknowledged that the current system of corporate taxation in the European Union (EU) hampers cross-border economic activities and impedes the creation and operations of multi-national business structures in Europe (Cnossen, 2002). Differences in national tax rates and capital income tax systems imply that investment and location decisions are, to a measurable degree, driven by tax considerations rather than by gross (social) returns on investment (Devereux and Griffith, 2001). Moreover, since due to the EU member states' uncoordinated tax schemes double taxation cannot be excluded, investment projects extending over several countries are often taxed more heavily than purely national projects.

In response to these problems the European Commission recently launched another report on company taxation in the EU (European Commission, 2001, Bolkestein Report). This report examines a number of remedies to remove obstacles to EU cross-border investment and suggests several comprehensive alternative taxation methods, deemed workable and politically feasible, to replace the current disarray of 15 (or, in the future, 25) corporate tax systems. Under each of these methods, firms face a single tax base for all their EU-wide activities such that corporate profits can be determined on the basis of the company's consolidated accounts rather than by separate accounting in each member state, as it is the case today. ${ }^{1}$ Obviously, any such method must determine how tax revenues emerging from this uniform tax base are allocated to EU member states. Following the example of the U.S. and Canada for the profit taxation of multi-state or multi-province firms, the Bolkestein report suggests the sharing of taxes levied on consolidated profits on the basis of what is called formula apportionment (FA).

Under a FA method, a corporation's tax liability to each country where it operates is determined as the product of its consolidated (total) international profits times that country's tax rate times the fraction of the corporation's activities in that country. This fraction is calculated by an apportionment formula made up of one or more indicators for business activities enter.

\footnotetext{
${ }^{1}$ The new proposals include so-called Common Base Taxation (CBT) and Home State Taxation (HST). Under CBT, the member states would harmonize their rules for computing the taxable profits of firms with cross-border operations, possibly maintaining national rules for purely domestic businesses. Under HST, member states keep their own rules for profit determination, but companies with cross-border operations would be taxed according to the rules of the member state where their headquarters are located. For a survey on these concepts (and other proposals in the EU report) see Weiner (2002a).
} 
Most common in North America is a three-part apportionment formula that calculates, for each state, a weighted average of the shares of a firm's total sales, payroll, and property that can be attributed to that state. ${ }^{2}$

By contrast, with the current EU scheme of taxation via separate accounting (SA) a firm's tax payment in a country is calculated as the product of the country's tax rate and the firm's profits earned in that country, the latter being determined according to national tax rules. A multinational firm, thus, has to establish separate accounts for its activities in each country where it operates. This creates strong incentives for firms to shift profits to low-tax countries. ${ }^{3}$ Moreover, SA incurs high administrative costs for EU companies since they have to deal with 15 tax systems in the EU, and high monitoring costs for the tax authorities of the EU member states.

Under FA, no internal transfer prices are needed anymore and, thus, the scope for tax evasion and tax exportation may be expected to be limited, as compared to the SA method. It is hoped that narrowing possibilities of tax shifting for firms translates, on the side of governments, into a weakening of the incentives for strategic tinkering with the tax code. A tax regime with smaller spillover effects might, thus, alleviate the problems of allocative inefficiencies and of harmful tax competition in the EU, both problems being induced by the current methods of taxation in the EU member states.

While intuition points to this appealing prospect, it is not at all clear whether, compared to the traditional SA method, FA taxation does indeed go along with smaller cross-border externalities and weaker goads for strategic taxation. Several authors have analysed and discussed spillover

\footnotetext{
${ }^{2}$ For a survey see Wildasin (2000). Suppose that a firm operates in $I$ states (or provinces) and earns total gross profits $\Pi$. Let, respectively, $F_{i}, W_{i}$, and $K_{i}$ represent sales (output), payroll, and property (capital) of a firm in state or province $i=1, \ldots, I ; F, W$, and $K$ denote total sales, payroll, and property in all states/provinces, respectively. Then the tax base for taxation in state $i$ is given by$$
\left(m_{F} \cdot \frac{F_{i}}{F}+m_{w} \cdot \frac{W_{i}}{W}+m_{K} \cdot \frac{K_{i}}{K}\right) \cdot \Pi
$$

The bracketed expression is the apportionment formula and the $m_{j}\left(m_{j} \geq 0\right.$ and $\left.\sum_{j} m_{j}=1\right)$ are the weights given to factors $j=F, W, K$ in the formula, and are gross total profits of the firm.

${ }^{3}$ Usually, profit shifting is achieved via transfer pricing (arm's length pricing) of intra-firm activities — which has, in turn, become a key instrument in firms' strive to evade taxes. See Bartelsman and Beetsma (2000) for empirical evidence.
} 
effects and distortions generated by FA methods (see, e.g., Gordon and Wilson, 1986; Goolsbee and Maydew, 2000; Anand and Sansing, 2000; Mintz, 2002). ${ }^{4}$ Two recent papers by Nielsen et al. (2002a,b) formally compare tax spillovers and their implications for tax competition under SA and under the FA method that uses property (capital) shares to apportion profits. They conclude that no clear-cut ranking of SA and FA taxation is possible with respect to externalities and tax competition.

While Nielsen et al. (2002a,b) focus on a single apportionment formula, the property-shares formula, and compare its performance relative to SA, the present paper will compare various methods of formula apportionment with respect to their allocative features and strategic incentives. Our analysis will be carried out in a fairly standard setting of international tax competition: In an economy with more than one taxing jurisdiction (called countries) and a common market, multinational corporations locate and operate in more than one country. Within the common market, a single and common tax base is used for profit taxation, and a FA method is used to allocate tax revenues to the individual countries. We will not specify a concrete formula from the outset, but rather derive general results for a reasonably restricted class of formulas that we call "uniform". This class encompasses the most widely discussed FA methods, namely apportionment according to property shares, payroll shares, and output shares and their convex combinations. The general approach allows us to plug in and compare specific formulas at later stages of the analysis. We distinguish two scenarios:

a) In the first setting, largely following Nielsen et al. (2002a), profit-maximizing multinational firms decide on capital investments in a domestic and a foreign plant and on the input of an overhead factor ("managerial services") that is shared by both plants.

b) In the second setting multinationals decide on both capital and labour input in their plants while overhead services are kept constant.

\footnotetext{
${ }^{4}$ These studies and the present one deal with externalities and distortions that arise among the jurisdictions that participate in the FA method. Spillovers to non-participating jursidictions are not discussd. It is a controversial issue associated with FA methods whether they should be applied only to corporate income earned within the group of participating countries in the FA method ("water's edge" taxation) or to worldwide income; see Weiner (2002b) for a discussion in the European context. A theoretical analysis of this question is, to our knowledge, still missing.
} 
For either scenario we assume that governments aim at maximizing their profit tax revenues. Since taxation has cross-border effects, governments are strategically interlinked and caught in a tax competition game. The outcome of this game depends on the apportionment method implemented in the common market. Our general result in both scenarios is that tax competition is sharper (i.e., equilibrium tax rates are lower) the more elastically the apportionment formula reacts upon tax changes. To substantiate this observation, we identify the factors determining the tax elasticity of the apportionment formulas and show that they consist of curvature properties of the underlying production technologies. As an application of this general result, we show for the first scenario that tax competition is — for all strictly concave technologies — sharpest under the property-share rule, followed by the sales-share rule and the payroll-share rule. For the second scenario we show that tax competition under the property- or the payroll-apportionment method is sharper than under the output-share formula. Whether the payroll- or the property-share formula generates tougher tax competition, depends on partial factor elasticities of production. The remainder of this paper is organized in six sections. Section 2 sets out the model. Sections 3 and 4 are devoted to the first scenario: Section 3 analyses the comparative statics of domestic and foreign factor demands with respect to tax changes under various FA regimes. Section 4 utilizes these results and derives our central results on tax competition for the first scenario. Section 5 goes roughly through the same series of excercises for the second, more complex scenario; the main findings are reported in Section 5.5. Section 6 concludes.

\section{A Model}

\subsection{Countries and Firms}

Following Nielsen et al. (2002a), we consider a common market with two countries, $A$ and $B$. Each country hosts a multinational firm that runs a subsidiary in the other country. A single output, the same for all firms, is produced and serves as the numéraire. Capital [small] letters indicate activities of government $A[B]$ or of the firm whose headquarters are located in $A[B]$. In each of its two entities, firm $A[B]$ produces its output with the same technology $F[f]$ that requires capital $K[k]$, labour $L[\ell]$, and "management services" $S[s]$ as inputs.

Capital can be invested in either of the two countries and will be denoted by $K_{A}$ and $K_{B}$ for 
firm $A$ and by $k_{A}$ and $k_{B}$ for firm $B$. Capital is in perfectly elastic supply and can be rented on world capital markets at an exogenous rate $\rho>0$ (for a leveraged firm) or must yield that rate of return $\rho$ if it is equity capital. ${ }^{5}$ Labour is a local factor of production whose input by firm $A[B]$ in country $i$ is denoted by $L_{i}\left[\ell_{i}\right]$. Until Section 6 we assume that the labour input cannot be adjusted in the short run (e.g., due to labour protection or other market inflexibilities). Management services comprise inputs jointly consumed in both entities of a firm. Under SA, the pricing of the use of $S$ in its foreign affiliate is a key instrument for shifting profits across business units. With FA, such profit shifting has no effect on the firm's overall tax burden. Nonetheless, $S$ will be treated as an endogenous factor of production in our analysis until Section 6 because different FA methods might impact on the demand for $S$ and, via cross-partial effects, indirectly on the location-specific factors capital and labour. We choose units of $S$ and $s$ such that their factor price is unity.

Total output and, thus, sales revenues of firm $A$ amount to

$$
F\left(K_{A}, S, L_{A}\right)+F\left(K_{B}, S, L_{B}\right)
$$

correspondingly, we obtain $f\left(k_{B}, s, \ell_{B}\right)+f\left(k_{A}, s, \ell_{A}\right)$ for firm $B$. For brevity, we will write $F^{A}:=F\left(K_{A}, S, L_{A}\right)$, and likewise $F^{B}, f^{A}$, and $f^{B}$. Production technologies are all wellbehaved. In particular, marginal productivities are positive and decreasing: $F_{x}>0$ and $F_{x x}<0$ for $x=K, S, L$; and similar for $f$. Moreover, we assume that $F$ and $f$ are strictly concave implying, in particular,

$$
F_{K K} F_{S S}-F_{K S}^{2}>0 \text { and } F_{K K} F_{L L}-F_{K L}^{2}>0
$$

for all $(K, S, L)$. Strict concavity ensures that corporate profits are strictly positive, which is an obvious requirement for any meaningful analysis of profit tax competition. We assume that capital and labour are essential for production: $F(0, S, L)=F(K, S, 0)=0$ for all $(K, S, L)$. Firm $A$ 's labour costs (payroll) in country $i$ is $W_{i}:=\omega_{i} L_{i}$ where $\omega_{i}$ is the wage rate in country $i$. With labour input being constant, labour costs are fixed costs. Total expenditures for inputs of firm $A$ then amount to $\rho \cdot\left(K_{A}+K_{B}\right)+S+W_{A}+W_{B}$. Subtracting total expenditure from

\footnotetext{
${ }^{5}$ We assume that multinationals are too small to impact on prices on (world) capital markets and, in Section 6 , on labour markets.
} 
revenues (1) yield gross profits of firm $A$ :

$$
F^{A}+F^{B}-\rho \cdot\left(K_{A}+K_{B}\right)-S-W_{A}-W_{B}
$$

Corresponding expressions apply to firm $B$.

\section{$2.2 \quad$ FA Taxation}

A multinational firm pays profit taxes to the government of each country where it operates. We assume that both countries share common rules of how to calculate consolidated profits of multi-national enterprises ${ }^{6}$ and adopt a formula apportionment (FA) method to calculate the shares of the firms' activities in their jurisdiction; these shares form the basis for the distribution of tax revenues. Denote country $A^{\prime}$ 's [B's] share of firm $i$ 's activities by $\alpha^{i}\left[\beta^{i}\right]$. The value of $\alpha^{i}$ is assumed to depend on how firm $i$ allocates its activities to the two countries. More specifically, for firm $A$ there exist functions $\alpha^{A}$ and $\beta^{A}$ such that

$$
\alpha^{A}=\alpha^{A}\left(K_{A}, K_{B}, S, L_{A}, L_{B}\right) \quad \text { and } \quad \beta^{A}=\beta^{A}\left(K_{B}, K_{A}, S, L_{B}, L_{A}\right)
$$

are the formula shares of profits assigned, respectively, to country $A$ and country $B$. Observe that the functional forms of $\alpha^{A}$ and $\beta^{A}$ in (3) are not restrictive let alone parametric. As special cases these functions include the most widely used formulas (exemplified for $\alpha^{A}$ below):

- FA according to capital (or property) shares: $\alpha^{A}=\frac{K_{A}}{K_{A}+K_{B}}$;

- FA according to sales (or output) shares: ${ }^{7} \alpha^{A}=\frac{F^{A}\left(K_{A}, S, L_{A}\right)}{F^{A}\left(K_{A}, S, L_{A}\right)+F^{B}\left(K_{B}, S, L_{B}\right)}$;

- FA according to payroll shares: $\alpha^{A}=\frac{W_{A}}{W_{A}+W_{B}}=\frac{\omega_{A} L_{A}}{\omega_{A} L_{A}+\omega_{B} L_{B}}$;

and, of course, convex combinations thereof (as illustrated in footnote 2). Other, more complex formulas are well conceivable. In the present scenario with fixed labour inputs payroll apportionment boils down to a simply tax-base sharing according to a constant fraction. In Section 5

\footnotetext{
${ }^{6}$ To date, EU member states apply different rules for calculating profits as a base for (national) taxation. To incorporate such differences into the formal model would render the analysis much more complex.

${ }^{7}$ Throughout we assume that plants only produce for the national markets where they are located. Thus, sales and outputs coincide. Given that we will mainly work in a setting with identical countries below, the assumption of zero ex- and imports (at least in equilibrium) seems natural, too.
} 
we will endogenize labour inputs and then investigate more thoroughly the impact of payroll FA.

In general, it is not all clear that countries $A$ and $B$ adopt formulas of the same type. In fact, this is a matter of strategic considerations and/or bilateral agreement (see Anand and Sansing, 2000). Therefore $\alpha^{A}$ and $\beta^{A}$ need not necessarily add up to unity. We will call a tax regime with FA uniform if the tax shares of the participating countries add up to one. For short, we will say that a system of uniform formulas is applied in our two-country world if, for all $\left(K_{i}, K_{j}, S, L_{i}, L_{j}\right), i, j=A, B, i \neq j$

$$
\alpha^{i}\left(K_{i}, K_{j}, S, L_{i}, L_{j}\right)+\beta^{i}\left(K_{j}, K_{i}, S, L_{j}, L_{j}\right)=1
$$

Obviously, if both countries adopt one and the same of the three simple formulas listed above or one and the same convex combination thereof, then their formulas are uniform. With uniform formulas, we can dispense with the symbol $\beta^{i}$ henceforth.

Capital costs are assumed to be non-deductible in the corporate tax base. For our analysis this assumption is innocuous since no substantial changes will occur if capital costs are fully or partially tax-deductible (also see Section 5.3 below). The profit tax only hits on

$$
\Phi:=F^{A}+F^{B}-S-W_{A}-W_{B}>0,
$$

which are the domestic firm's earnings before interest and taxes (EBIT). Denoting by $t^{i}$ country $i$ 's statutory tax rate for corporate profits, the total tax burden of firm $i$ under FA is

$$
\left(\alpha^{A} \cdot t^{A}+\beta^{A} \cdot t^{B}\right) \cdot \Phi
$$

The bracketed expression denotes the effective average tax rate which firm $A$ faces for its operations in the common market; we will refer to it by $\tau^{A}$. Observe that the effective tax rate is, via $\alpha^{A}$ and $\beta^{A}$, a function of the firm's activities:

$$
\tau^{A}=\tau^{A}\left(K_{A}, K_{B}, S, L_{A}, L_{B}\right)=\alpha^{A}\left(K_{A}, K_{B}, S, L_{A}, L_{B}\right) \cdot t^{A}+\beta^{A}\left(K_{A}, K_{B}, S, L_{A}, L_{B}\right) \cdot t^{B}
$$

Net profits $\Pi$ of firm $A$ are then given by

$$
\Pi=\left(1-\tau^{A}\left(K_{A}, K_{B}, S, L_{A}, L_{B}\right)\right) \cdot \Phi\left(K_{A}, K_{B}, S\right)-\rho\left(K_{A}+K_{B}\right) .
$$




\subsection{Profit Maximization}

We will focus on the production plan of firm $A$. The subsequent analysis will also apply to firm $B$, mutatis mutandis. Firm $A$ chooses $K_{A}, K_{B}$, and $S$ as to maximize (7). The FOCs for an interior solution of this program are given by (subscripts to functions denote partial derivatives):

$$
\begin{aligned}
-\frac{\partial \tau^{A}}{\partial K_{A}} \cdot \Phi+\left(1-\tau^{A}\right) \cdot F_{K}^{A}-\rho & =0 \\
-\frac{\partial \tau^{A}}{\partial K_{B}} \cdot \Phi+\left(1-\tau^{A}\right) \cdot F_{K}^{B}-\rho & =0 \\
-\frac{\partial \tau^{A}}{\partial S} \cdot \Phi+\left(1-\tau^{A}\right) \cdot\left(F_{S}^{A}+F_{S}^{B}-1\right) & =0 .
\end{aligned}
$$

Here,

$$
\frac{\partial \tau^{A}}{\partial x}=t^{A} \cdot \alpha_{x}^{A}+t^{B} \cdot \beta_{x}^{A}
$$

( $\left.x=K_{A}, K_{B}, S\right)$ can be quite complicated expressions, depending on the formula applied. Observe that for uniform formulas $\left(\alpha^{A}+\beta^{A} \equiv 1\right)$, we have

$$
\frac{\partial \tau^{A}}{\partial x}=\left(t^{A}-t^{B}\right) \cdot \alpha_{x}^{A}
$$

for $x=K_{A}, K_{B}, S$. Under FA methods, taxation does not only affect the factor allocation through its direct effects on net marginal factor returns (the second terms on the LHS in (8a) to (8c)), but also indirectly: Firms influence their apportionment-determined, effective tax rates $\tau^{i}$ through input choices (the first terms on the LHS of (8a) through (8c)). $\partial \tau^{A} / \partial x \neq 0$ for $x=K_{A}, K_{B}$ or $S$ indicates that to maximize its profits the firm needs to account for the dependence of its effective tax rate on its choice variables. In fact, the firm would unnecessarily increase its overall tax load by disregarding this relationship. It is not a priori clear whether this indirect effect is positive or negative. ${ }^{8}$

Observe that without taxation, firms' decisions lead to equalisation of the marginal productivities of capital across locations,

$$
F_{K}^{A}=F_{K}^{B}=\rho
$$

\footnotetext{
${ }^{8}$ Weiner $(2002 \mathrm{a}, \mathrm{b})$ refers to positive and negative effects as an additional "tax" or a "subsidy" in the FA method. This is, strictly speaking, only appropriate when firms would not change their production plans upon a switch to a FA tax rule. See Weiner (2002b) for more on corporate tax planning under FA tax regimes.
} 
and to a demand for managerial services according to the Samuelson-type condition

$$
F_{S}^{A}+F_{S}^{B}=1
$$

\section{Tax Rate Effects}

How will firms respond to changes in tax rates? This question is not only relevant from an allocative point of view, but also for policy-makers since tax changes translate into changes in tax revenues, GDP, and social welfare. Responses to tax changes under a FA method are more difficult to determine than under spearate accounting (with linear tax schedules) since in the former case firms do not only influence the tax base, but also their effective tax rate.

In this section we derive, discuss, and compare the reactions of firm $A$ to an increase in country $A$ 's statutory tax rate $t^{A}$. All other comparative statics can be obtained by similar tokens. Moreover, to facilitate the analysis we will impose further restrictions:

- Full symmetry: Both countries are identical. More specifically, technolgies are the same across firms, labour input and wage rates are the same $\left(L_{A}=L_{B}, W_{A}=W_{B}\right)$, and governments have set equal tax rates in the initial situation: $t^{A}=t^{B}=t$.

- Uniform formulas: Condition (4) holds.

As a consequence of these assumptions, the inituial situation will be characterized, first, by (11a) and (11b), second, by identical amounts of investment $\left(K_{A}=K_{B}\right)$, third, by $\tau_{x}=0$ for $x=K_{A}, K_{B}, S ;$ cf. (10), and fourth, by $\tau^{A}=t$.

A further implication of symmetry will turn out to be helpful for comparative statics: We can confine our analysis to changes of $t^{A}$ and of firm $A$ 's instruments. Variations in $t^{B}$ or in the foreign firm's instruments follow one-by-one according to the following pattern:

$$
\begin{gathered}
\frac{\partial K_{B}}{\partial t^{B}}=\frac{\partial K_{A}}{\partial t^{A}}=\frac{\partial K_{A}}{\partial t^{A}}=\frac{\partial K_{B}}{\partial t^{B}} \\
\frac{\partial K_{A}}{\partial t^{B}}=\frac{\partial K_{B}}{\partial t^{A}}=\frac{\partial K_{A}}{\partial t^{B}}=\frac{\partial K_{A}}{\partial t^{B}} \\
\frac{\partial S}{\partial t^{B}}=\frac{\partial S}{\partial t^{A}}=\frac{\partial s}{\partial t^{B}}=\frac{\partial s}{\partial t^{B}} .
\end{gathered}
$$




\subsection{Comparative Statics}

Under the simplifying conditions of symmetry and uniform formulas, it can be shown (after some term shuffling) that the comparative statics of (8a) through (8c) with respect to a tax change in $A$ can be described by the following set of equations:

$$
\mathbf{M} \cdot\left(\begin{array}{c}
\partial K_{A} / \partial t^{A} \\
\partial K_{B} / \partial t^{A} \\
\partial S / \partial t^{A}
\end{array}\right)=\gamma
$$

where

$$
\mathbf{M}:=(1-t) \cdot\left(\begin{array}{ccc}
F_{K K}^{A} & 0 & F_{K S}^{A} \\
0 & F_{K K}^{B} & F_{K S}^{B} \\
F_{K S}^{A} & F_{K S}^{B} & F_{S S}^{A}+F_{S S}^{B}
\end{array}\right) \quad \text { and } \gamma:=\left(\begin{array}{c}
\alpha^{A} F_{K}^{A}+\alpha_{K_{A}}^{A} \Phi \\
\alpha^{A} F_{K}^{B}+\alpha_{K_{B}}^{A} \Phi \\
\alpha_{S}^{A} \Phi
\end{array}\right)
$$

Note that, due to symmetry, $F_{K}^{A}=F_{K}^{B}, F_{K K}^{A}=F_{K K}^{B}, F_{K S}^{A}=F_{K S}^{B}, F_{S S}^{A}=F_{S S}^{B}$, and $K_{A}=K_{B}$. Hence, we can dispense with country indexes. Note that

$$
\operatorname{det} \mathbf{M}=2(1-t)^{3} \cdot F_{K K} \cdot\left(F_{K K} F_{S S}-F_{K S}^{2}\right)
$$

is negative with $F$ being strictly concave. From Cramer's Rule, the signs of the comparative statics of $K_{A}, K_{B}$, and $S$ with respect to $t^{A}$ are then given by the opposites of the signs of the determinants of $\mathbf{M}_{1}, \mathbf{M}_{2}$, and $\mathbf{M}_{3}$, respectively, where $\mathbf{M}_{i}$ is the matrix obtained from $\mathbf{M}$ by replacing its $i$-th column by $\gamma$. I.e.,

$$
\begin{aligned}
& \operatorname{sgn}\left\{\frac{\partial K_{A}}{\partial t^{A}}\right\}=-\operatorname{sgn}\left\{\operatorname{det} \mathbf{M}_{1}\right\} \\
& =-\operatorname{sgn}\left\{2 \alpha^{A} F_{K} F_{K K} F_{S S}+\right. \\
& \left.+\Phi \cdot\left[\alpha_{K_{A}}^{A} \cdot\left(2 F_{K K} F_{S S}-F_{K S}^{2}\right)+\alpha_{K_{B}}^{A} F_{K S}^{2}-\alpha_{S}^{A} F_{K S} F_{K K}\right]\right\} ; \\
& \operatorname{sgn}\left\{\frac{\partial K_{B}}{\partial t^{A}}\right\}=-\operatorname{sgn}\left\{\operatorname{det} \mathbf{M}_{2}\right\} \\
& =-\operatorname{sgn}\left\{2 \alpha^{A} F_{K} F_{K K} F_{S S}+\right. \\
& \left.+\Phi \cdot\left[\alpha_{K_{A}}^{A} F_{K S}^{2}+\alpha_{K_{B}}^{A} \cdot\left(2 F_{K K} F_{S S}-F_{K S}^{2}\right)+\alpha_{S}^{A} F_{K S} F_{K K}\right]\right\} ; \\
& \operatorname{sgn}\left\{\frac{\partial S}{\partial t^{A}}\right\}=-\operatorname{sgn}\left\{\operatorname{det} \mathbf{M}_{3}\right\} \\
& =-\operatorname{sgn}\left\{2 \alpha^{A} F_{K} F_{K K} F_{K S}-\Phi \cdot\left[F_{K K} F_{K S}\left(\alpha_{K_{A}}^{A}+\alpha_{K_{B}}^{A}\right)-\alpha_{S}^{A} F_{K K}^{2}\right]\right\} .
\end{aligned}
$$


It is worth noticing that eqs. (14a) through (14c) would be considerably more complicated without the assumptions of uniform formulas and symmetry. But even in the simple cases we are considering here the effects of tax rate changes on input choices turn out to depend, in quite complex ways, on the properties of technologies and apportionment formulas. Unfortunately, eqs. (14a) through (14c) are too general to yield informative results. Yet with more specific functional forms a number of interesting implications can be elicited.

Separable production functions. In the rather special case of $F_{K S}=0$, comparative statics (14a) to (14c) become quite simple. First, we observe from (14a) that

$$
\operatorname{sgn}\left\{\frac{\partial K_{A}}{\partial t^{A}}\right\}=-\operatorname{sgn}\left\{\alpha^{A} F_{K}+\alpha_{K_{A}}^{A} \Phi\right\} .
$$

Hence, higher taxes in $A$ drive capital out of that country $\left(\partial K_{A} / \partial t^{A}<0\right)$ whenever - as one should reasonably assume - higher investments in $A$ do not reduce that country's tax share in the formula: $\alpha_{K_{A}}^{A} \geq 0$.

Second, from (14b),

$$
\operatorname{sgn}\left\{\frac{\partial K_{B}}{\partial t^{A}}\right\}=-\operatorname{sgn}\left\{\alpha^{A} F_{K}+\alpha_{K_{B}}^{A} \Phi\right\}
$$

If one plausibly assumes that higher investments abroad reduce the domestic country's tax share in the apportionment formula, $\alpha_{K_{B}}^{A}<0$, this expression is ambiguous in sign. It is easy to show that a tax raise in $A$ reduces capital investments in $B$ if and only if, in absolute terms, the elasticity of country $A$ 's tax share $\alpha$ with respect to $K_{B}$ is larger than the elasticity of EBIT with respect to $K_{B}$ :

$$
\frac{\partial K_{B}}{\partial t^{A}}>0 \Longleftrightarrow\left|\frac{\alpha_{K_{B}}^{A} K_{B}}{\alpha^{A}}\right|>\frac{F_{K} K_{B}}{\Phi} .
$$

E.g., under FA with sales shares, $\alpha^{A}=F^{A} /\left(F^{A}+F^{b}\right)$, this condition can be shown to always hold in symmetric settings. However, that does not extend to other formulas, leaving the effects of tax increases on foreign investment unclear.

Finally, from (14c),

$$
\operatorname{sgn}\left\{\frac{\partial S}{\partial t^{A}}\right\}=-\operatorname{sgn} \alpha_{S}^{A},
$$

i.e., the input of managerial services decreases when the home country's tax rate is raised if the domestic tax share increases with that input. For most formulas, $\alpha_{S}^{A}=0$ in a symmetric 
allocation. For these cases, the input choice for $S$ will not be affected by the tax rate in a symmetric setting: $\partial S / \partial t^{A}=0$.

Next we introduce functional specifications other than separability of technologies (i.e., $F_{K S} \neq 0$ is admitted).

FA with property shares. Assume that $\alpha^{A}=K_{A} /\left(K_{A}+K_{B}\right)$. Clearly, $\alpha_{S}^{A} \equiv 0$. For the symmetric case, we further get $\alpha^{A}=1 / 2$ and $\alpha_{K_{A}}^{A}=-\alpha_{K_{B}}^{A}=1 /(4 K)$. Inserting this specification into (14a) through (14c), we replicate the expressions obtained by Nielsen et al. (2002a, eq. (15)):

$$
\begin{aligned}
\operatorname{sgn}\left\{\frac{\partial K_{A}}{\partial t^{A}}\right\} & =-\operatorname{sgn}\left\{F_{K} F_{K K} F_{S S}+\frac{\Phi}{2 K} \cdot\left[F_{K K} F_{S S}-F_{K S}^{2}\right]\right\}<0 ; \\
\operatorname{sgn}\left\{\frac{\partial K_{B}}{\partial t^{A}}\right\} & =-\operatorname{sgn}\left\{F_{K} F_{K K} F_{S S}-\frac{\Phi}{2 K} \cdot\left[F_{K K} F_{S S}-F_{K S}^{2}\right]\right\} ; \\
\operatorname{sgn}\left\{\frac{\partial S}{\partial t^{A}}\right\} & =\operatorname{sgn} F_{K S} .
\end{aligned}
$$

FA with output/sales shares. Let $\alpha^{A}=F^{A} /\left(F^{A}+F^{B}\right)$. Again, $\alpha^{A}=1 / 2$ for the symmetric case. Furthermore, $\alpha_{K_{A}}^{A}=-\alpha_{K_{B}}^{A}=F_{K} /(4 F)$. Verify that

$$
\alpha_{S}^{A}=\frac{F^{B} F_{S}^{A}-F^{A} F_{S}^{B}}{\left(F^{A}+F^{B}\right)^{2}}=0
$$

in the symmetric case. Hence, eqs. (14a) to (14c) are turned into

$$
\begin{aligned}
\operatorname{sgn}\left\{\frac{\partial K_{A}}{\partial t^{A}}\right\} & =-\operatorname{sgn}\left\{F_{K} F_{K K} F_{S S}+\frac{F_{K} \Phi}{2 F} \cdot\left[F_{K K} F_{S S}-F_{K S}^{2}\right]\right\}<0 ; \\
\operatorname{sgn}\left\{\frac{\partial K_{B}}{\partial t^{A}}\right\} & =-\operatorname{sgn}\left\{F_{K} F_{K K} F_{S S}-\frac{F_{K} \Phi}{2 F} \cdot\left[F_{K K} F_{S S}-F_{K S}^{2}\right]\right\} ; \\
\operatorname{sgn}\left\{\frac{\partial S}{\partial t^{A}}\right\} & =\operatorname{sgn} F_{K S} .
\end{aligned}
$$

FA with payroll shares. In this case, $\alpha^{A}=W^{A} /\left(W^{A}+W^{B}\right)$. Trivially, $\alpha_{K_{A}}^{A}=\alpha_{K_{B}}^{A}=$ $\alpha_{S}^{A} \equiv 0$ and $\alpha^{A}=1 / 2$ for symmetry. Obviously, then,

$$
\frac{\partial K_{A}}{\partial t^{A}}<0, \quad \frac{\partial K_{B}}{\partial t^{A}}<0, \quad \text { and } \quad \operatorname{sgn}\left\{\frac{\partial S}{\partial t^{A}}\right\}=\operatorname{sgn} F_{K S} .
$$

The main observations from this series of examples are now summarized as follows: 
Proposition 1 Suppose that either the technology is separable $\left(F_{K S}=0\right)$ or that the apportionment formula uses property shares, output shares, or payroll shares.

a) An increase in a country's profit tax rate induces the domestic firm to reduce its investment in that country: $\frac{\partial K_{A}}{\partial t^{A}}<0$ and, analogously, $\frac{\partial K_{B}}{\partial t^{B}}<0$.

b) With the exception of a formula with payroll shares, it is unclear whether an increase in a country's profit tax rate induces the domestic firm to increase or to reduce its foreign investment.

c) If $F_{K S}=0$, the firm reacts to an increase in a country's profit tax rate by reducing its overhead if $\alpha_{S}^{i}>0$. No reaction is necessary when $\alpha_{S}^{i}=0$. If $F_{K S} \neq 0$, the sign of $F_{K S}$ determines under the most widely used formulas whether an increase in a country's profit tax makes the domestic firm to reduce or increase its overhead.

Proposition 1 shows that increases in a country's tax rate tends to drive the mobile factor capital out of that country; this is a standard feature of profit taxation. However, Proposition 1 also demonstrates that firms do not necessarily react on an increase in one country's tax rate by increasing the employment of capital in the other country.

Since the cross-border effects of tax hikes on investment are ambiguous, it is interesting to know whether a unilateral tax increase can lead to a surge in overall (worldwide) investment. Due to symmetry we only need to consider the effects of $t^{A}$ on the domestic firm's total capital demand. We invoke (14a) and (14b) to calculate:

$$
\operatorname{sgn}\left\{\frac{\partial\left(K_{A}+K_{B}\right)}{\partial t^{A}}\right\}=-\operatorname{sgn}\left\{F_{K K} F_{S S} \cdot\left(2 \alpha^{A} F_{K}+\Phi \cdot\left(\alpha_{K_{A}}^{A}+\alpha_{K_{B}}^{A}\right)\right)\right\} .
$$

Many apportionment formulas and, in particular, the three formulas just discussed possess the property that $\alpha_{K_{A}}^{A}=-\alpha_{K_{B}}^{A}$ in a symmetric allocation (but of course not necessarily elsewhere). Under this condition we obtain from (19)

Proposition 2 If $\alpha_{K_{A}}^{A}=-\alpha_{K_{B}}^{A}$ in a symmetric allocation, a tax increase will always reduce total investments. 


\subsection{Comparing Formulas}

We now compare the comparative static effects of tax changes across three specific apportionment formulas: property shares (indexed $K$ ), sales/output shares (indexed $F$ ), and payroll shares (indexed $W$ ). Starting from a symmetric equilibrium, such a comparison across formulas is indeed admissable since in the initial situation all these three formulas lead to the same factor allocation characterized by (11a) and (11b). We then find:

Proposition 3 Starting from a symmetric equilibrium with uniform formulas,

a) the impact of a tax increase on the demand of managerial services is the same under the three apportionment formulas;

b) the negative impact of a tax increase on the domestic firm's domestic investment is, in absolute terms, largest under the property-share formula, followed by the output-share and the payroll share formula:

$$
\left.\frac{\partial K_{A}}{\partial t^{A}}\right|_{K}<\left.\frac{\partial K_{A}}{\partial t^{A}}\right|_{F}<\left.\frac{\partial K_{A}}{\partial t^{A}}\right|_{W}<0
$$

c) the (generally ambiguous) impact of a tax increase in the home country on the foreign investment of the home firm is, in absolute terms, largest under a property-shares formula, followed by the output-share and the payroll-share formula:

$$
\left.\frac{\partial K_{B}}{\partial t^{A}}\right|_{W}<\left.\frac{\partial K_{B}}{\partial t^{A}}\right|_{F}<\left.\frac{\partial K_{B}}{\partial t^{A}}\right|_{K}
$$

d) the negative impact of a tax increase on the domestic firm's total investment is the same for all three formulas:

$$
\left.\frac{\partial\left(K_{A}+K_{B}\right)}{\partial t^{A}}\right|_{W}=\left.\frac{\partial\left(K_{A}+K_{B}\right)}{\partial t^{A}}\right|_{F}=\left.\frac{\partial\left(K_{A}+K_{B}\right)}{\partial t^{A}}\right|_{K} .
$$

Proof: Since the initial allocations under all three formulas are identical, $\operatorname{det} \mathbf{M}$ in (13) is identical in all cases too. Thus, the marginal effects of $t^{A}$ on $K_{A}, K_{B}$, or $S$ can be ranked by comparing the values of the determinants of, respectively, $\mathbf{M}_{1}, \mathbf{M}_{2}$, and $\mathbf{M}_{3}$ for the three formulas. As $\mathbf{M}_{3}$ is the same for all formulas, item a) of the proposition follows immediately. The effects of $t^{A}$ on $K_{A}$ are inversely ranked by the values of $\operatorname{det} \mathbf{M}_{1}$ in (14a), evaluated for 
the three formulas. For the payroll formula, we obtain $\left.\operatorname{det} \mathbf{M}_{1}\right|_{W}=F_{K} F_{K K} F_{S S}$, while the corresponding expressions for the two other formulas appear in (16a) and (17a). Obviously, $\left.\operatorname{det} \mathbf{M}_{1}\right|_{W}$ is the smallest of these three. Comparing the remaining two, we obtain

$$
\left.\left.\operatorname{det} \mathbf{M}_{1}\right|_{K} \frac{>}{<} \operatorname{det} \mathbf{M}_{1}\right|_{F} \quad \Longleftrightarrow \quad \frac{F_{K} K}{F} \frac{<}{>}
$$

Since $F(0, S, L)=0$ and $F$ is strictly concave in $K$, the partial production elasticity of capital is less than unity (marginal productivity always falls short of average productivity), and hence we get $\left.\operatorname{det} \mathbf{M}_{1}\right|_{K}>\left.\operatorname{det} \mathbf{M}_{1}\right|_{F}$. This proves item b) of the proposition.

Item c) follows by a similar token. Item d) can be readily seen from (19) recalling that $\alpha_{K_{A}}^{A}+\alpha_{K_{B}}^{A}=0$ for all three formulas.

Proposition 3 states for the FA rules under consideration that the effects of an increase in $t^{A}$ on domestic investment are (among the three rules considered) strongest for property-share apportionment and weakest for the payroll-share formula. This ranking reverses in case of foreign investment. The aggregate, i.e., the sum of domestic and foreign, investment effect is the same for all rules.

While domestic investment will be reduced in response to a tax increase in the home country under either tax rule, foreign investment might react quite differently under different formulas. It is conceivable that a tax increase leads to an increase in foreign investment when a property-share formula is applied while the same tax increase would lead to a decrease of foreign investment under sales-based apportionment. In their comparison of the effects of tax increases under separate accounting and FA with a property-share formula, Nielsen et al. (2002a) find that the effects on domestic [foreign] investment are stronger [weaker] under FA than under SA. Our results suggest that the formula scrutinized by Nielsen et al. (2002a) is the most favorable for such a comparison and that it is not clear whether their finding also holds for other apportionment methods. Extending Nielsen et al.'s analysis to other apportionment formulas is, however, beyond the scope of the present paper. 


\section{Tax Competition among Leviathan Governments}

\subsection{Comparing Equilibria}

Government $A$ 's tax revenues are given by

$$
T^{A}=\alpha^{A} \cdot t^{A} \cdot \Phi
$$

Suppose that governments strive for maximizing its tax revenues. With some simple re-arranging of terms we calculate that

$$
\begin{aligned}
\frac{\partial T^{A}}{\partial t^{A}}= & \overbrace{\alpha^{A} \Phi+t^{A}\left(\alpha_{S}^{A} \Phi-\alpha^{A}\right) \frac{\partial S}{\partial t^{A}}+t^{A} \alpha^{A}\left(F_{K}^{A}+F_{K}^{B}\right)\left(\frac{\partial K_{A}}{\partial t^{A}}+\frac{\partial K_{B}}{\partial t^{A}}\right)} \\
& +t^{A} \Phi\left[\alpha_{K_{A}}^{A} \frac{\partial K_{A}}{\partial t^{A}}+\alpha_{K_{B}}^{A} \frac{\partial K_{B}}{\partial t^{A}}\right]
\end{aligned}
$$

Obviously, a zero tax rate can never be optimal as $\partial T^{A} /\left.\partial t^{A}\right|_{t^{A}=0}>0$. Since the setting is perfectly symmetric, so will be equilibria. Verify that, by Proposition 3, items a) and d), the overbraced terms in (23) are identical for property, payroll, and sales apportionment methods. Further recall that in a symmetric situation $\alpha_{K_{A}}^{A}=-\alpha_{K_{B}}^{A}>0$ holds for all rules. Hence, the only difference in the marginal revenue effects of $t^{A}$ under the various rules is in the differences $\left(\partial K_{A} / \partial t^{A}\right)-\left(\partial K_{B} / \partial t^{A}\right)$. Now use Proposition 3 , items b) and c), to obtain

$$
\left.\frac{\partial T^{A}}{\partial t^{A}}\right|_{K}<\left.\frac{\partial T^{A}}{\partial t^{A}}\right|_{F}<\left.\frac{\partial T^{A}}{\partial t^{A}}\right|_{W}
$$

at all levels of $\left(t^{A}, t^{B}\right)$. Hence, the reaction function $t^{A}\left(t^{B}\right)$ - which is implicitly defined by $\partial T^{A} / \partial t^{A}=0$ - for payroll apportionment lies above that for sales apportionment which in turn lies above that for property apportionment. The same pattern holds for country $B$. Therefore, we obtain

Proposition 4 In a symmetric Nash-equilibrium of the Leviathan tax competition game with FA, the level of taxation will be highest with a payroll formula, followed by sales-and property formulas:

$$
\left(t^{A}, t^{B}\right)_{W}>\left(t^{A}, t^{B}\right)_{F}>\left(t^{A}, t^{B}\right)_{K}
$$

According to Proposition 4, tax competition is sharpest with a FA method that uses capital shares, followed by output shares, and finally payroll shares. This ranking is in full accordance 
with a general principle that emerges from many models on (Leviathan-type) tax competition: Tax competition is sharper the more elastic is the tax base with respect to tax changes. To see that this rule also applies here, recall from (23) that, starting from a symmetric allocation, the change in the tax base is entirely determined by the reaction of the formula share $\alpha^{A}$ on changes in $t^{A}$. Using our previous findings, it is straightforward to calculate:

$$
\begin{aligned}
\left.\frac{\partial \alpha^{A}}{\partial t^{A}}\right|_{K} & =\frac{1}{K^{2}} \cdot \frac{\Phi\left(F_{K K} F_{S S}-F_{K S}^{2}\right)}{4 N}<0 \\
\left.\frac{\partial \alpha^{A}}{\partial t^{A}}\right|_{F} & =\frac{F_{K}^{2}}{F^{2}} \cdot \frac{\Phi\left(F_{K K} F_{S S}-F_{K S}^{2}\right)}{4 N}<0 \\
\left.\frac{\partial \alpha^{A}}{\partial t^{A}}\right|_{W}=0 &
\end{aligned}
$$

Here, $N$ is a negative term, a multiple of $\operatorname{det} \mathbf{M}$ used above. The elasticity of $\alpha^{A}$ is, in absolute terms, lowest (precisely: zero) for the payroll formula, which is a trivial result since labor inputs are constant by assumption. Furthermore, $\partial \alpha^{A} /\left.\partial t^{A}\right|_{K}<\partial \alpha^{A} /\left.\partial t^{A}\right|_{F}$ iff $F>F_{K} K$, which holds for all concave technologies. Hence, under a property-share formula, the tax share of country $A$ reacts most elastically upon tax changes (in absolute terms). As this also holds for country $B$, mutatis mutandis, tax competition between $A$ and $B$ turns out to be sharpest.

\subsection{Assessing Equilibria}

We now briefly compare the Nash equilibrium to the cooperative solution of joint revenue maximization. First observe that the (symmetric) cooperative solution $\left(t^{*}, t^{*}\right)$ (i.e., the maximizer of the problem $\max T^{A}+T^{B}$ ) is common to all three formulas we are discussing here. Whether the cooperative solution lies below [above] the non-cooperative solution depends on whether the revenue externality $\partial T^{A} / \partial t^{B}$ is negative [positive], if evaluated at the Nash equilibrium. Unfortunately, the sign of $\partial T^{A} / \partial t^{B}$ is generally unclear. All we are able to show is that for payroll apportionment (which, in the present setting, is a constant-share apportionment) $\partial T^{A} / \partial t^{B}$ is negative, implying that the Nash equilibrium is characterized by tax rates being too high: $\left(t^{A}, t^{B}\right)_{W}>\left(t^{*}, t^{*}\right)$. For sales- or property-apportionment (where tax shares vary with factor choices), such a ranking is not possible. 


\section{The Model with Endogenous Capital and Labour Choices}

\subsection{The Setting}

In the previous sections we assumed labour to be a fixed factor. Owing to this assumption the formula apportionment with payroll shares boils down to a constant rule. Although the assumption of constant labour inputs might be warranted in a short-run perspective by inflexibilities in the labour market, it ought certainly to be dropped if we wish to assess the full and long-run effects of various FA methods.

Therefore we now assume that multinational enterprises choose both labour and capital inputs for their plants in countries $A$ and $B$. To keep the analysis tractable we now hold managerial input $S$ constant. As before, our analysis will start from an initial equilibrium with perfect symmetry. Hence it is sufficient, again, to only consider the domestic firm's choices and the effects tax policy exerts on them. Firm $A$ chooses $K_{A}, K_{B}, L_{A}$, and $L_{B}$ to maximize net profits

$$
\Pi=\left(1-\tau^{A}\left(K_{A}, K_{B}, S\right)\right) \cdot \Phi\left(K_{A}, K_{B}, L_{A}, L_{B}\right)-\rho\left(K_{A}+K_{B}\right)
$$

where $\tau^{A}=t^{B}+\left(t^{A}-t^{B}\right) \alpha^{A}$ is the effective tax rate and

$$
\Phi\left(K_{A}, K_{B}, L_{A}, L_{B}\right):=F^{A}\left(K_{A}, \bar{S}, L_{A}\right)+F^{B}\left(K_{B}, \bar{S}, L_{B}\right)-\bar{S}-\omega \cdot\left(L_{A}+L_{B}\right)>0
$$

again denotes earnings before interest and taxes. Here we assume that the wage rate is the same in both countries $\left(\omega_{A}=\omega_{B}=\omega\right)$ and that labour markets are perfectly competitive. Unlike capital costs, labour costs are assumed to be deductible from the profit tax base. We will comment on this provision below. With a uniform formula, the set of FOCs is:

$$
\begin{aligned}
-\left(t^{A}-t^{B}\right) \alpha_{K_{A}}^{A} \Phi+\left(1-\tau^{A}\right) F_{K}^{A}-\rho & =0 \\
-\left(t^{A}-t^{B}\right) \alpha_{K_{B}}^{A} \Phi+\left(1-\tau^{A}\right) F_{K}^{B}-\rho & =0 \\
-\left(t^{A}-t^{B}\right) \alpha_{L_{A}}^{A} \Phi+\left(1-\tau^{A}\right)\left[F_{L}^{A}-\omega\right] & =0 \\
-\left(t^{A}-t^{B}\right) \alpha_{L_{B}}^{A} \Phi+\left(1-\tau^{A}\right)\left[F_{L}^{B}-\omega\right] & =0 .
\end{aligned}
$$

In a symmetric situation with $t^{A}=t^{B}$ and under a uniform formula (26a) to (26d) yields $F_{K}^{A}=F_{K}^{B}$ and $F_{L}^{A}=F_{L}^{B}=\omega$. Consequently, $K_{A}=K_{B}=K$ and $L_{A}=L_{B}=L$. 


\subsection{Comparative Statics}

With $t^{A}=t^{B}$ in the initial situation the comparative statics of (26a) through (26d) with respect to a tax change in $A$ are described by the following system of equations:

$$
\left(1-\tau^{A}\right) \cdot\left(\begin{array}{cccc}
F_{K K}^{A} & 0 & F_{K L}^{A} & 0 \\
0 & F_{K K}^{B} & 0 & F_{K L}^{B} \\
F_{K L}^{A} & 0 & F_{L L}^{A} & 0 \\
0 & F_{K L}^{B} & 0 & F_{L L}^{B}
\end{array}\right) \cdot\left(\begin{array}{c}
\partial K_{A} / \partial t^{A} \\
\partial K_{B} / \partial t^{A} \\
\partial L_{A} / \partial t^{A} \\
\partial L_{B} / \partial t^{A}
\end{array}\right)=\left(\begin{array}{c}
\gamma_{1} \\
\gamma_{2} \\
\gamma_{3} \\
\gamma_{4}
\end{array}\right)
$$

where

$$
\begin{aligned}
\gamma_{1} & :=\alpha_{K_{A}}^{A} \Phi+F_{K}^{A} \alpha^{A} \\
\gamma_{2} & :=\alpha_{K_{B}}^{A} \Phi+F_{K}^{B} \alpha^{A} \\
\gamma_{3} & :=\alpha_{L_{A}}^{A} \Phi+\left[F_{L}^{A}-\omega\right] \alpha^{A}=\alpha_{L_{A}}^{A} \Phi \\
\gamma_{4} & :=\alpha_{L_{B}}^{A} \Phi+\left[F_{L}^{B}-\omega\right] \alpha^{A}=\alpha_{L_{B}}^{A} \Phi,
\end{aligned}
$$

where $\gamma_{3}$ and $\gamma_{4}$ presuppose a symmetric setting. Due to symmetry we can dispense with country indexes again. It is straightforward that

$$
\operatorname{det} \mathbf{M}=\left(F_{K K} F_{L L}-F_{K L}^{2}\right)^{2}>0,
$$

where $\mathbf{M}$ is the matrix on the LHS of (27) Denote by $\mathbf{M}_{i}$ the matrix that emerges from replacing the $i$-th column in $\mathbf{M}$ by the $\gamma$-vector. From Cramer's Rule,

$$
\begin{aligned}
\frac{\partial K_{A}}{\partial t^{A}} & =\frac{\operatorname{det} \mathbf{M}_{1}}{(1-t) \operatorname{det} \mathbf{M}}=\frac{\left(F_{K K} F_{L L}-F_{K L}^{2}\right) \cdot\left[\gamma_{1} F_{L L}-\gamma_{3} F_{K L}\right]}{(1-t)\left(F_{K K} F_{L L}-F_{K L}^{2}\right)^{2}} \\
& =\frac{\gamma_{1} F_{L L}-\gamma_{3} F_{K L}}{(1-t)\left(F_{K K} F_{L L}-F_{K L}^{2}\right)} \\
\frac{\partial K_{B}}{\partial t^{A}} & =\frac{\gamma_{2} F_{L L}-\gamma_{4} F_{K L}}{(1-t)\left(F_{K K} F_{L L}-F_{K L}^{2}\right)} \\
\frac{\partial L_{A}}{\partial t^{A}} & =\frac{\gamma_{3} F_{K K}-\gamma_{1} F_{K L}}{(1-t)\left(F_{K K} F_{L L}-F_{K L}^{2}\right)} \\
\frac{\partial L_{B}}{\partial t^{A}} & =\frac{\gamma_{4} F_{K K}-\gamma_{2} F_{K L}}{(1-t)\left(F_{K K} F_{L L}-F_{K L}^{2}\right)} .
\end{aligned}
$$

It is reasonable to assume that higher investment or labour input in country $A[B]$ do not decrease [do not increase] country $A$ 's tax share:

$$
\alpha_{K_{A}}^{A}, \alpha_{L_{A}}^{A} \geq 0 \geq \alpha_{K_{B}}^{A}, \alpha_{L_{B}}^{A}
$$


This provided, we obtain

Proposition 5 Suppose that (29) holds.

- If $F_{K L} \geq 0$, then a tax increase in country $A$ reduces investment $K_{A}$, lower employment $L_{A}$, and lower output $F^{A}$.

A tax increase in $A$ will increase employment in $B$, while the effects on investment and output in that country are ambiguous.

If furthermore $\alpha_{x_{A}}^{A}=-\alpha_{x_{B}}^{A}$ (with $x=K, L$ ) in a symmetric allocation, then a tax increase will always lead to a decrease in total investments $K_{A}+K_{B}$, total employment $L_{A}+L_{B}$ and, thus, total output $F^{A}+F^{B}$.

- If $F_{K L}<0$, then the effects of an increase in $t^{A}$ on $K_{A}, K_{B}, L_{A}$, and $L_{B}$ are ambiguous.

Proof: If (29) holds, $\gamma_{1}, \gamma_{3}>0$ while the signs of $\gamma_{2}$ and $\gamma_{4}$ are unclear. Combined with $F_{K L} \geq 0$, this leads to unambiguously negative comparative static effects for $K_{A}$ and $L_{A}$. Otherwise the effects are unclear.

To get the effects on $K_{A}+K_{B}$ and $L_{A}+L_{B}$ verify that, if $\alpha_{K_{A}}^{A}=-\alpha_{K_{B}}^{A}, \gamma_{1}+\gamma_{2}=2 \alpha^{A} F_{K}=F_{K}$ and $\gamma_{3}+\gamma_{4}=0$. Use this when summing up the single effects.

Proposition 5 covers the three most widely used formula methods: FA according to capital shares, payroll shares, and output or sales shares. The assumption that the marginal productivity of either factor increases with an increase in the input of the other $\left(F_{K L}>0\right)$ is satisfied by most commonly used production functions. In particular, it holds for Cobb-Douglas technologies. Proposition 5 is the analogue of Proposition 1 and both propositions yield about the same message: If a government raises its profit tax rate, it will - under fairly mild restrictions on the FA method and on production technologies - drive economic activities out of its jurisdiction. The cross-border effects of tax increases remain ambiguous, however.

\subsection{Digression: Tax-Deductible Cost of Capital}

So far, we assumed that the costs of capital are not deductible from the profit tax base, while labour expenditures are. Let us now briefly discuss the implications of allowing for tax-deductible 
interest payments. As a first consequence, the FOCs (26a) and (26b) for profit maximization with respect to investments are modified to

$$
\begin{aligned}
& -\left(t^{A}-t^{B}\right) \alpha_{K_{A}}^{A} \Phi+\left(1-\tau^{A}\right)\left[F_{K}^{A}-\rho\right]=0 \\
& -\left(t^{A}-t^{B}\right) \alpha_{K_{B}}^{A} \Phi+\left(1-\tau^{A}\right)\left[F_{K}^{B}-\rho\right]=0
\end{aligned}
$$

In a symmetric initial situation we have $F_{K}^{A}=F_{K}^{B}=\rho$. The first two components in the vector $\gamma$ in (27) will then read $\gamma_{1}=\alpha_{K_{A}}^{A} \Phi>0$ and $\gamma_{2}=\alpha_{K_{B}}^{A} \Phi<0$. As a consequence, a tax increase in $A$ will unambiguously lead to additional investments of capital in $B$ when $F_{K L}>0$. Hence, we can tighten the corresponding result of Proposition 5. Moreover, if $\alpha_{K_{B}}^{A}=-\alpha_{K_{A}}^{A}$ in a symmetric allocation, a tax increase in $A$ does neither affect total investment nor total employment (since $\gamma_{1}+\gamma_{2}=\gamma_{3}+\gamma_{4}=0$ in this case). Yet, total output $F^{A}+F^{B}$ will decrease: The initial situation is characterized by international production efficiency. Shifting factors from $A$ to $B$ will then lead to a decline in worldwide production. We sum this up in

Proposition 6 Assume that interest costs are deductible from the profit tax base. Suppose that (29) holds and that $F_{K L} \geq 0$. Then a tax increase in country $A$ leads to smaller investment $K_{A}$, lower employment $L_{A}$, and lower output $F^{A}$. It increases investment $K_{B}$, employment $L_{B}$ and output $F^{B}$.

If furthermore $\alpha_{x_{A}}^{A}=-\alpha_{x_{B}}^{A}$ for $x=K, L$ in a symmetric allocation, then a tax increase in $A$ will leave total investment and total employment unchanged. Total output $F^{A}+F^{B}$ will, however, decrease:

$$
\frac{\partial K_{A}}{\partial t^{A}}=-\frac{\partial K_{B}}{\partial t^{A}}, \quad \frac{\partial L_{A}}{\partial t^{A}}=-\frac{\partial L_{B}}{\partial t^{A}}, \quad \text { and } \quad \frac{\partial\left(F^{A}+F^{B}\right)}{\partial t^{A}}<0 .
$$

The results on comparative statics and on equilibria in tax competition games to be presented below do not depend on the asymmetry in the tax treatment of capital and labour costs. We can therefore proceed under the assumption of an asymmetric tax treatment without loss of generality.

\subsection{Comparing Formulas}

We now compare the comparative statics of tax changes for the three formulas already analysed in Section 5.2. First observe that a payroll-share in our setting is equivalent to a labour share 
formula:

$$
\alpha^{A}=\frac{W^{A}}{W^{A}+W^{B}}=\frac{\omega L_{A}}{\omega L_{A}+\omega L_{B}}=\frac{L_{A}}{L_{A}+L_{B}} .
$$

Table 1 summarizes the numerators of $(28 \mathrm{a})$ to $(28 \mathrm{~d})$ for the three formulas. ${ }^{9}$ Comparing the numerators suffices for a comparison since in a symmetric setting the denominators are identical for all three formulas.

Table 1 goes here.

The following result is immediate from Table 1:

Proposition $7 \quad$ a) Comparing property-share and payroll-share formulas yields:

$$
\begin{aligned}
\left.\left.\left.\left.\frac{\partial K_{A}}{\partial t^{A}}\right|_{K} \frac{\partial K_{A}}{<t^{A}}\right|_{W} \quad \Longleftrightarrow \frac{\partial K_{B}}{\partial t^{A}}\right|_{K} \frac{<}{>} \frac{\partial K_{B}}{\partial t^{A}}\right|_{W} \quad \Longleftrightarrow \quad \frac{F_{L L}}{K} \frac{F_{K L}}{L}-\frac{F}{L} \\
\left.\frac{\partial L_{A}}{\partial t^{A}}\right|_{K} \geq\left.\left.\frac{\partial L_{A}}{\partial t^{A}}\right|_{W} \quad \Longleftrightarrow \frac{\partial L_{B}}{\partial t^{A}}\right|_{K} \leq\left.\frac{\partial L_{B}}{\partial t^{A}}\right|_{W} \quad \Longleftrightarrow \quad-\frac{F_{K L}}{K} \frac{F_{K K}}{L} .
\end{aligned}
$$

b) Comparing property-share and output-share formulas yields:

$$
\begin{aligned}
& \left.\frac{\partial K_{A}}{\partial t^{A}}\right|_{K} \geq\left.\left.\left.\frac{\partial K_{A}}{\partial t^{A}}\right|_{F} \Longleftrightarrow \frac{\partial K_{B}}{\partial t^{A}}\right|_{K} \frac{\leq}{>} \frac{\partial K_{B}}{\partial t^{A}}\right|_{F} \Longleftrightarrow \frac{F_{L L}}{K} \frac{F_{K} F_{L L}-F_{L} F_{K L}}{F} \\
& \left.\left.\left.\frac{\partial L_{A}}{\partial t^{A}}\right|_{K} \frac{\geq}{<} \frac{\partial L_{A}}{\partial t^{A}}\right|_{F} \Longleftrightarrow \frac{\partial L_{B}}{\partial t^{A}}\right|_{K} \leq\left.\frac{\partial L_{B}}{\partial t^{A}}\right|_{F} \Longleftrightarrow \frac{F_{K L}}{K} \frac{F_{L} F_{K K}-F_{K} F_{K L}}{F} .
\end{aligned}
$$

c) Comparing payroll-share and output-share formulas yields:

$$
\begin{gathered}
\left.\left.\left.\left.\frac{\partial K_{A}}{\partial t^{A}}\right|_{W} \frac{>}{<} \frac{\partial K_{A}}{\partial t^{A}}\right|_{F} \Longleftrightarrow \frac{\partial K_{B}}{\partial t^{A}}\right|_{W} \frac{\leq}{>} \frac{\partial K_{B}}{\partial t^{A}}\right|_{F} \Longleftrightarrow-\frac{F_{K L}}{L} \frac{F_{K} F_{L L}-F_{L} F_{K L}}{F} \\
\left.\frac{\partial L_{A}}{\partial t^{A}}\right|_{W} \geq\left.\left.\frac{\partial L_{A}}{\partial t^{A}}\right|_{F} \Longleftrightarrow \frac{\partial L_{B}}{\partial t^{A}}\right|_{W} \leq\left.\frac{\partial L_{B}}{\partial t^{A}}\right|_{F} \Longleftrightarrow \frac{F_{K K}}{L} \frac{F_{L} F_{K K}-F_{K} F_{K L}}{F} .
\end{gathered}
$$

d) Comparing total effects: ${ }^{10}$

The effects of a tax increase on total investment $K_{A}+K_{B}$ and on total employment $L_{A}+L_{B}$ are identical across all three formulas.

\footnotetext{
${ }^{9}$ In case we allowed for interest cost deductibility we would get $Q_{1}=Q_{2}=0$ in Table 1 . It is easy to see that this would not affect any of the comparisons across formulas presented in the following propositions.

${ }^{10}$ From (28a) to (28d) it is easy to verify that equality of total effects holds for all uniform formulas that satisfy, under symmetry, that $\alpha_{K_{A}}^{A}=-\alpha_{K_{B}}^{A}$ and similar for labour.
} 
Although the results of Proposition 7 look quite complicated, they are, in essence, very similar to those reported in Proposition 3. First, Proposition 7 shows that the comparative statics under different formulas can be neatly ranked by simple terms involving production and the properties of technology. We will further comment on this below. Second, Proposition 7 shows that the ranking of the three formulas with respect to the strength of domestic tax effects is exactly inverse to the ranking with respect to cross-border effects.

More specific results can be obtained from Proposition 7 by assuming that technologies are homogeneous of degree $r<1$ :

Corollary 7.1 Assume that technologies are homogeneous of degree $r<1$. Then:

$$
\begin{aligned}
& \left.\frac{\partial K_{A}}{\partial t^{A}}\right|_{K}<\left.\frac{\partial K_{A}}{\partial t^{A}}\right|_{W}<0 \quad \text { and }\left.\quad \frac{\partial K_{B}}{\partial t^{A}}\right|_{K}>\left.\frac{\partial K_{B}}{\partial t^{A}}\right|_{W} \\
& 0>\left.\frac{\partial L_{A}}{\partial t^{A}}\right|_{K}>\left.\frac{\partial K_{A}}{\partial t^{A}}\right|_{W} \quad \text { and }\left.\quad \frac{\partial L_{B}}{\partial t^{A}}\right|_{K}<\left.\frac{\partial K_{A}}{\partial t^{A}}\right|_{W} .
\end{aligned}
$$

Proof: Homogeneity of degree lower than one (i.e., $K F_{K}+L F_{L}=r \cdot F$ with $r<1$ ) implies, by differentiation with respect to $L$, that $K F_{K L}+L F_{L L}=(r-1) F_{L}<0$, and, by differentiation with respect to $K$, that $L F_{K L}+K F_{K K}=(r-1) F_{K}<0$. The corollary follows from invoking these inequalities in the first item of Proposition 7.

The ranking derived in Corollary 7.1 makes intuitive sense: If a formula targets directly at one factor (as with payroll and property shares), then profit tax changes have a greater impact on that factor than under a formula that does not target this factor. Corollary 7.1 does not allow for a ranking of the output-share formula. Further restricting technologies to Cobb-Douglas functions enables us to explicitly calculate the expressions on the far RHS in Proposition 7. This straightforwardly leads to

Corollary 7.2 Assume that technologies are Cobb-Douglas: $F(K, \bar{S}, L)=g(\bar{S}) \cdot K^{\beta} \cdot L^{\delta}$ with $\beta, \delta \in(0,1)$ and $\beta+\delta<1$. Then:

$$
\left.\frac{\partial K_{A}}{\partial t^{A}}\right|_{K}<\left.\frac{\partial K_{A}}{\partial t^{A}}\right|_{F}<\left.\frac{\partial K_{A}}{\partial t^{A}}\right|_{W}<0
$$




$$
0>\left.\frac{\partial L_{A}}{\partial t^{A}}\right|_{K}>\left.\frac{\partial K_{A}}{\partial t^{A}}\right|_{F}>\left.\frac{\partial K_{A}}{\partial t^{A}}\right|_{W} .
$$

The reverse ranking holds regarding the effects of $t^{A}$ on $K_{B}$ and $L_{B}$.

This corollary confirms the intuiton we already provided for Corollary 7.1: Output-share apportionment targets both factors; the tax impacts under that regime therefore lie in between those of the "direct" payroll- and property-share formulas.

It is worth emphasizing that Corollaries 7.1 and 7.2 were established for special cases of technologies only. As Proposition 7 reveals, the ranking of effects across formulas depends, in a non-trivial way, on the concavity properties of the production function. It is well conceivable that under some technologies the tax effect on capital is larger with a formula that is only indirectly targeted at capital than with an explicit property-shares rule.

\subsection{Leviathan-Type Tax Competition}

Let us now turn to a comparison of governments' incentives in a Leviathan-type tax competition game. As before, the tax revenues that government $A$ aims to maximize are given by $T^{A}=$ $\alpha^{A} \cdot t^{A} \cdot \Phi$; similar for government $B$. In a symmetric setting, Nash equilibria are symmetric too.

Proposition 8 - Tax competition under a property-share rule leads to lower tax rates in the Nash equilibrium than tax competition under a output-share rule, $\left.\left(t^{A}, t^{B}\right)\right|_{K}<\left.\left(t^{A}, t^{B}\right)\right|_{F}$, if and only if

$$
\frac{F_{L L}}{K^{2}}<\frac{F_{K}^{2} F_{L L}-2 F_{L} F_{K} F_{K L}+F_{L}^{2} F_{K K}}{F^{2}}
$$

- Tax competition under a payroll-share rule leads to lower tax rates in the Nash equilibrium than tax competition under an output-share rule, $\left.\left(t^{A}, t^{B}\right)\right|_{L}<\left.\left(t^{A}, t^{B}\right)\right|_{F}$, if and only if

$$
\frac{F_{L L}}{K^{2}}<\frac{F_{K K}}{L^{2}}
$$

- Tax competition under a property-share rule leads to lower tax rates in the Nash equilibrium than tax competition under an output-share rule, $\left.\left(t^{A}, t^{B}\right)\right|_{K}<\left.\left(t^{A}, t^{B}\right)\right|_{F}$, if and only if

$$
\frac{F_{K K}}{L^{2}}<\frac{F_{K}^{2} F_{L L}-2 F_{L} F_{K} F_{K L}+F_{L}^{2} F_{K K}}{F^{2}} .
$$


Proof: Taking the partial derivative of $T^{A}$ with respect to $t^{A}$ yields:

$$
\frac{\partial T^{A}}{\partial t^{A}}=\overbrace{\alpha^{A} \Phi+t^{A} \alpha^{A}\left(\Phi_{K_{A}} \frac{\partial K_{A}}{\partial t^{A}}+\Phi_{K_{B}} \frac{\partial K_{B}}{\partial t^{A}}+\Phi_{L_{A}} \frac{\partial L_{A}}{\partial t^{A}}+\Phi_{L_{B}} \frac{\partial L_{B}}{\partial t^{A}}\right)}+\alpha^{A} t^{A} \Omega
$$

where

$$
\begin{aligned}
\Omega:=\frac{\partial \alpha^{A}}{\partial t^{A}} & =\alpha_{K_{A}}^{A} \frac{\partial K_{A}}{\partial t^{A}}+\alpha_{K_{B}}^{A} \frac{\partial K_{B}}{\partial t^{A}}+\alpha_{L_{A}}^{A} \frac{\partial L_{A}}{\partial t^{A}}+\alpha_{L_{B}}^{A} \frac{\partial L_{B}}{\partial t^{A}} \\
& =\alpha_{K_{A}}^{A}\left(\frac{\partial K_{A}}{\partial t^{A}}-\frac{\partial K_{B}}{\partial t^{A}}\right)+\alpha_{L_{A}}^{A}\left(\frac{\partial L_{A}}{\partial t^{A}}-\frac{\partial L_{B}}{\partial t^{A}}\right)
\end{aligned}
$$

Verify that, by the last item of Proposition 7, the overbraced terms in (31) are identical for property, payroll, and sales apportionment methods (recall that $\Phi_{L_{A}}=\Phi_{L_{B}}=0, \Phi_{K_{A}}=$ $\Phi_{K_{B}}=F_{K},{ }^{11}$ and $\left.\alpha_{K_{A}}^{A}=-\alpha_{K_{B}}^{A}\right)$. Hence, the partial effects only differ by the term labelled $\Omega$. From (32) (where we also employed the equality $\alpha_{K_{A}}^{A}=-\alpha_{K_{B}}^{A}$ ) and Table 1 we calculate:

$$
\begin{aligned}
\Omega_{K} & =N \cdot \frac{F_{L L}}{K^{2}} \\
\Omega_{F} & =N \cdot \frac{F_{K}^{2} F_{L L}-2 F_{L} F_{K} F_{K L}+F_{L}^{2} F_{K K}}{F^{2}} \\
\Omega_{W} & =N \cdot \frac{F_{K K}}{L^{2}}
\end{aligned}
$$

where subscripts to $\Omega$ indicate the formula under consideration and where $N:=\Phi /(8(1-$ $\left.\left.t^{A}\right)\left(F_{K K} F_{L L}-F_{K L}^{2}\right)\right)$ is a common positive multiplier. Thus,

$$
\begin{aligned}
\left.\frac{\partial T^{A}}{\partial t^{A}}\right|_{K} \leq\left.\frac{\partial T^{A}}{\partial t^{A}}\right|_{F} \quad \Longleftrightarrow \quad \frac{F_{L L}}{K^{2}} \frac{\leq F_{K}^{2} F_{L L}-2 F_{L} F_{K} F_{K L}+F_{L}^{2} F_{K K}}{F^{2}} \\
\left.\left.\frac{\partial T^{A}}{\partial t^{A}}\right|_{K} \frac{\partial T^{A}}{\partial t^{A}}\right|_{W} \quad \Longleftrightarrow \quad \frac{F_{L L}}{K^{2}} \frac{\leq F_{K K}}{L^{2}} \\
\left.\left.\frac{\partial T^{A}}{\partial t^{A}}\right|_{W} \frac{\partial T^{A}}{\partial t^{A}}\right|_{F} \quad \Longleftrightarrow \quad \frac{F_{K K}}{L^{2}} \frac{F_{K}^{2} F_{L L}-2 F_{L} F_{K} F_{K L}+F_{L}^{2} F_{K K}}{F^{2}} .
\end{aligned}
$$

The reaction function of country $A$ under FA method $x=K, F, W$ is implicitly defined by $\partial T^{A} /\left.\partial t^{A}\right|_{x}=0$. Hence, conditions (34a) to (34c) determine the positions of the reaction functions in the various tax competition games relative to each other and, in turn, allow us to compare Nash equilibria. We exemplify this for the comparison of property and sales apportionment here; all other comparisons follow the same pattern: Suppose, e.g., that $\partial T^{A} /\left.\partial t^{A}\right|_{K}>\partial T^{A} /\left.\partial t^{A}\right|_{F}$ in

\footnotetext{
${ }^{11}$ In case that interest costs were deductible from the profit tax base we would obtain $\Phi_{K_{A}}=\Phi_{K_{B}}=F_{K}-\rho$, which obviously would not affect the argument.
} 
(34a). Then country $A$ 's reaction function under property apportionment lies above that under sales apportionment. Due to symmetry, country $B$ 's reaction functions possess the same property. Hence, the reaction functions intersect at higher tax rates under property apportionment than under sales apportionment. Going through this argument for all cases yields the claim.

Proposition 8 relates the tax rates that emerge in the equilibrium of a Leviathan-type tax competition game to concavity features of the production technology. In principle, conditions (30a) to (30c) are easy to check. It should be noted, however, that these conditions will not be satisfied globally in general. ${ }^{12}$

The proof of Proposition 8 reveals that for alternative formulas differences in the strategic incentives for taxation only arise from the term

$$
\Omega=\frac{\partial \alpha^{A}}{\partial t^{A}},
$$

defined in (32). This observation suggests an elasticity interpretation of Proposition 8 analogous to Proposition 4: Tax competition is sharper the greater the elasticity of the tax formula with respect to tax changes. Further insights into this general result can be obtained by restricting technologies to Cobb-Douglas functions:

Proposition 9 Suppose that technologies are Cobb-Douglas: $F(K, \bar{S}, L)=g(\bar{S}) \cdot K^{\beta} \cdot L^{\delta}$ with $\delta+\beta<1$.

- Tax competition under a property-share rule leads to lower tax rates in the Nash equilibrium than tax competition under a payroll-share rule if and only if $\beta<\delta$.

- Tax competition under an output-share always leads to higher tax rates in the Nash equilibrium than tax competition under either a payroll or a property share rule.

Proof: For Cobb-Douglas functions calculate from (33a) to (33c)

$$
\begin{aligned}
& \Omega_{K}=\delta(\delta-1) \cdot K^{\beta-2} L^{\delta-2} \cdot N ; \\
& \Omega_{F}=\beta(\beta-1) \cdot K^{\beta-2} L^{\delta-2} \cdot N ; \\
& \Omega_{W}=-\delta \beta(\delta+\beta) \cdot K^{\beta-2} L^{\delta-2} \cdot N .
\end{aligned}
$$

\footnotetext{
${ }^{12}$ Proposition 8 is imprecise in so far as conditions (30a) to (30c) have to hold in the initial symmetric situation from which we suppose the tax competition game to start.
} 
The claim follows from observing that $\delta+\beta<1 .{ }^{13}$

Proposition 9 conveys two important messages:

- When formulas directly targeted at one factor are used (such as payroll- and propertyshare rules), then the technological factor elasticities $\beta$ and $\delta$ determine the sharpness of international tax competition.

- When output-share formula is implemented that at the same time targets both factors of production, by design, then tax competition is mitigated (regardless of the magnitudes of the factor elasticities).

\section{Concluding Remarks}

In this paper, we analyse the effects of various types of FA methods on the strategic incentives for Leviathan governments to set their profit tax rates. We use a simple model of two identical countries. Each country hosts a profit-maximizing multinational firm that runs a subsidiary in the other country. The firm decides on domestic and foreign investments of capital and, depending on the scenario, on the demands for managerial services (a factor that all of its plants share) or for labour in each of its locations. Input choices depend, in quite complex ways, on profit tax rates and on the FA method that is applied.

For the strategic interaction among governments operating under a FA method, our model yields a general insight: Tax competition is sharper (i.e., equilibrium tax rates are lower) the more elastically the apportionment formula reacts upon tax changes.

While the thrust of this finding is well-known from many other studies on tax competition, the challenge in our setting is to identify the conditions determining the magnitudes of the elasticities of the apportionment formulas. We trace back these conditions to properties of production technologies and provide some general, yet simple-to-verify, qualifiers. Apportionment formulas can be based on one or more indicators for business activities. The present paper offers results for quite general formulas but also provides informative insights for more specific, parametric

\footnotetext{
${ }^{13}$ The function $h(x)=x(x-1)$ is increasing in $x$ if and only if $x>0.5$. Hence, for $\beta>0.5$, the inequality $\delta(\delta-1)>\beta(\beta-1)$ only holds if $\delta>\beta>0.5$. But then $\beta+\delta>1$ which violates the presupposition $\beta+\delta<1$.
} 
formulas. Confining this summary to the three most prominent (parametric) apportionment methods, namely property-, payroll-, and output-share formulas, we find:

- If labour input is fixed, tax competition is for all strictly concave technologies sharpest under the property-share rule, followed by the sales-share rule and the payroll-share rule.

- If both capital and labour input choices are endogenous and technologies are Cobb-Douglas, then tax competition under the property- and the payroll-apportionment method (which both target only one of the production factors) is sharper than under the output-share formula (which targets both inputs). Whether the payroll- or the property-share formula gives rise to fiercer tax competition, depends on the relative magnitudes of the labour and capital shares in production.

Our simple model can be extended in various directions:

- Tinkering with the formulas: What are the strategic incentives when governments use weighted formulas such as:

$$
\alpha^{A}=m_{K} \cdot \frac{K_{A}}{K_{A}+K_{B}}+m_{F} \cdot \frac{F^{A}}{F^{A}+F^{B}}+m_{W} \cdot \frac{L_{A}}{L_{A}+L_{B}}
$$

with $m_{K}+m_{F}+m_{W}=1$ ? How do strategic governments choose the weights in their apportionment formula? Investigating these questions could relate our approach to Anand and Sansing (2000) who show that governments have an incentive to employ different formulas while a uniform formula would be the preferred choice from a co-operative perspective.

- Asymmetric formulas and countries: Since governments are unlikely to agree on a uniform formula it is important to know the impact on tax competition among governments that use different formulas. Likewise, tax competition among countries of different size is a further step towards realism. Both extensions introduce asymmetries into the model. In view of the complexies we already encountered in the symmetric settings studied here, these extensions can be expected to pose substantial analytical challenges.

- Government objectives other than revenue maximization: Nielsen et al. (2002a) show that the criteria to compare tax competition under SA and under FA with property-shares basically apply to governments that are either tax revenue maximizers or welfare maximizers. 
One may want to check whether this is also true for comparing tax competition equilibria under various methods of FA.

- Comparison between FA and separate accounting: Nielsen et al. (2002a) find that, under property-share, FA tax increases have a stronger [weaker] impact on domestic [foreign] investment than under SA. From our analysis, it is doubtful whether this observation carries over to other FA methods as well. This issue calls for clarification.

Nielsen et al. (2002a) have a central policy message for the European Union striving to reform its current (and messy) system of corporate profit taxation in favour of a (hopefully better structured) method: If that reform involves formula apportionment to allocate tax revenues to EU member states, then it is not necessarily clear whether tax competition will be mitigated within Europe. The principal message from our analysis is that incentives for strategic taxation under FA depend on the attributes of the apportionment formula to be implemented. Tax competition in the EU can be mitigated by choosing a tax-inelastic apportionment formula. However, whether one formula is less elastic than another typically depends on properties of the production technologies — and therefore is an empirical issue.

\section{References}

Anand, Bharat, and Richard Sansing, 2000. The Weighting Game: Formula Apportionment as an Instrument of Public Policy. National Tax Journal 53, 183-199.

Bartelsman, Eric J., and Roel M.W.J. Beetsma, 2000, Why Pay More? Corporate Tax Avoidance through Transfer Pricing in OECD Countries. CESifo Working Paper No. 324, Munich.

Cnossen, Sijbren, 2002, Tax Policy in the European Union: A Review of Issues and Options. CESifo Working Paper No. 758, Munich.

Devereux, Michael P., and Rachel Griffith, 2001, Summary of the "Devereux and Griffith"

Economic Model and Measures of Effective Tax Rates. Annex A of European Commission (2001).

European Commission, 2001, Company Taxation in the Internal Market. COM(2001), 582final: Brussels. 
Goolsbee, Arthur, and E. Maydew, 2000, Coveting Thy Neighbor's Manufacturing: The Dilemma of State Income Apportionment. Journal of Public Economics 75, 125-143.

Gordon, Roger, and John D. Wilson, 1986, An Examination of Multijurisdictional Corporate Income Taxation under Formula Apportionment. Econometrica 54, 1357-1373.

Mintz, Jack M., 2002, Company Taxation and the Internal Market. CESifo Forum 1/2002, 3-9 (Munich).

Nielsen, Søren Bo, Pascalis Raimondos-Møller, and Guttorm Schjelderup, 2002, Tax Spillovers under Separate Accounting and Formula Apportionment. EPRU Discussion Paper, Copenhagen.

Nielsen, Søren Bo, Pascalis Raimondos-Møller, and Guttorm Schjelderup, 2002, Formula Apportionment and Transfer Pricing under Oligopolistic Competition. Forthcoming, Journal of Public Economic Theory.

Weiner, Joann Martens, 2002a, Formula Apportionment and the Future of Company Taxation in the European Union. CESifo Forum 1/2002, 10-20 (Munich).

Weiner, Joann Martens, 2002b, Formula Apportionment in the EU: A Dream Come True or the EU's Worst Nightmare? CESifo Working Paper No. 667, Munich.

Wildasin, David, 2000, State and Provincial Corporate Income Taxation. Current Practice and Policy Issues for the United States and Canada. Canadian Tax Journal 48, 424-441. 


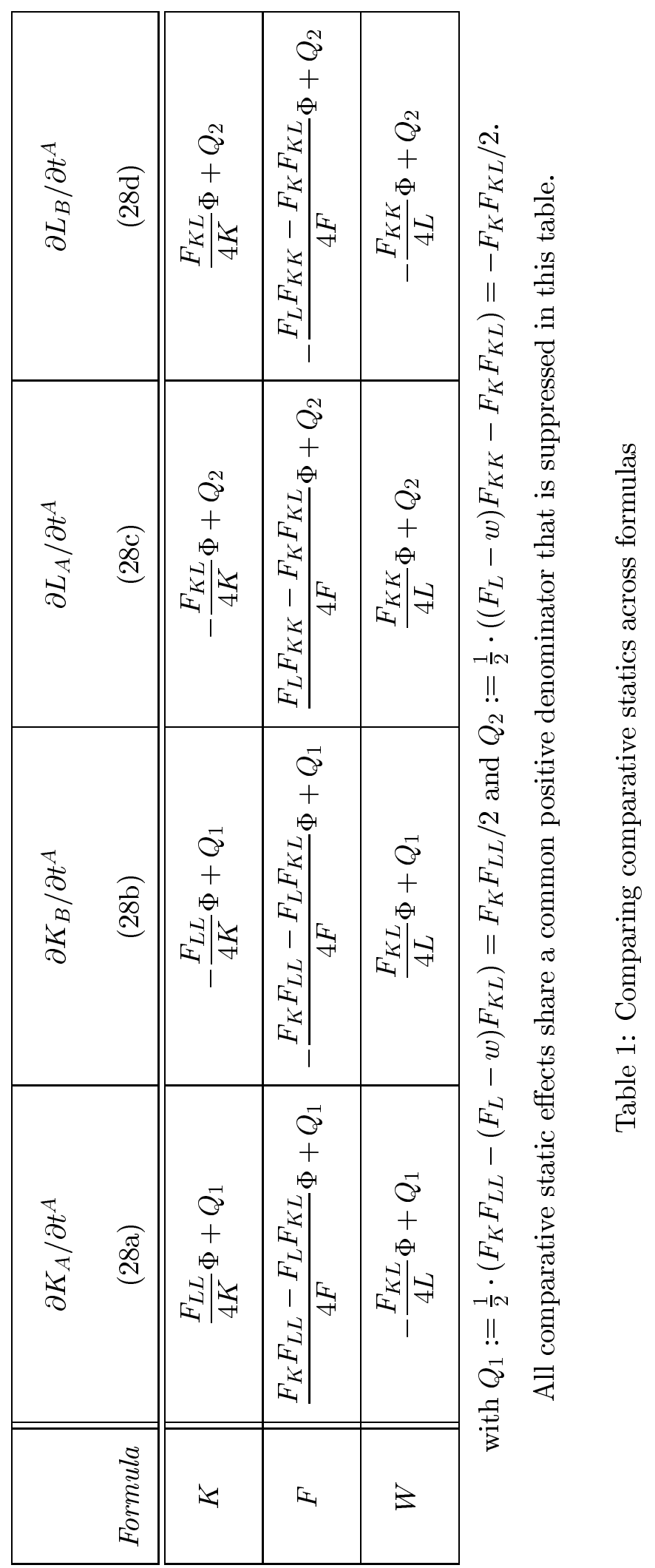

